\title{
Conflict in the Multicultural Counseling Classroom: Counselor Educators' Experiences
}

\author{
Marsha J. Milan \\ Palo Alto University, Los Altos \\ Corinne W. Bridges \\ Walden University
}

\begin{abstract}
We gathered data from counselor educators to study their experiences with emotionally charged exchanges while teaching multicultural counseling. We then used descriptive phenomenology and an ecological systems framework to reveal the emotions counselor educators experienced and the outcomes of the exchanges. We discuss the implications of our findings for counselor preparation programs and educators.
\end{abstract}

Keywords: counselor educators, emotionally charged exchanges, multicultural counseling competence, descriptive phenomenology, ecological systems theory

\section{Introduction}

Multicultural counseling courses feature emotional engagement (Dickson, Argus-Calvo, \& Tafoya, 2010; Pernell-Arnold, Finley, Sands, Bourjolly, \& Stanhope, 2012), unlike the emotional distance present in other academic fields in higher education (Yoon, Jérémie-Brink, \& Kordesh, 2014). Multicultural counseling instructors might evoke strong emotions when they present sensitive topics, such as privilege and oppression (Burton \& Furr, 2014; Toporek \& Worthington, 2014). The emotionality can intensify as educators shape future counselors' behaviors to include professional values (Ametrano, 2014; Francis \& Dugger, 2014; Swank \& Adcock, 2014). Counselors in training have experienced guilt, anger, and shame (Mindrup, Spray, \& Lamberghini-West, 2011); anxiety and frustration (Toporek \& Worthington, 2014); and disbelief and confusion (Warner, Phelps, Pittman, \& Moore, 2013) during their multicultural counseling courses. Moreover, students have resisted accepting information they learned about themselves that was incongruent with their existing selfidentity (Howell, Gaither, \& Ratliff, 2015) and have expressed their resistance by "projecting intense feelings, especially anger, onto the instructor" (Yoon et al., 2014, p. 364) and "punishing the educator" (Helms et al., 2003, p. 40). Hence, multicultural counseling educators have experienced emotionally charged exchanges (Burton \& Furr, 2014), defined here as an escalation in emotional intensity during interactions with students.

The emotionality common during multicultural counseling training has the potential to impact teacher-learner rapport, as evidenced by students harassing the teacher (Helms et al., 2003), complaining to authorities at the university, and providing a poor evaluation for a course (Reynolds, 2011). The rapport between educators and students can affect teaching outcomes (Nixon et al., 2010) and student participation, recall, knowledge, and skills development (Frisby \& Martin, 2010). Teaching effectiveness has been linked to students' multicultural competence (Hill, Vereen, McNeal, \& Stotesbury, 2013); thus, emotionally charged exchanges might affect counselor educators' ability to foster their students' multicultural counseling competence.

Please address queries to: Marsha Milan, 7259 1st Street, Marine City, MI 48039. Email:

marshamilannichols@gmail.com 
Despite the negative effects of emotional exchanges, there is a lack of research on counselor educators' experiences with emotionally charged exchanges related to teaching multicultural counseling (Arredondo \& Tovar-Blank, 2014; Pernell-Arnold et al., 2012), which indicated the need for an explorative study (Ponterotto, 2013). Therefore, the purpose of this study was to gain an understanding of counselor educators' experiences with emotionally charged exchanges while teaching multicultural counseling. Based on this purpose, the research question was "What are counselor educators' experiences with emotionally charged exchanges while teaching multicultural counseling?"

\section{Method}

We employed the descriptive phenomenological design (Giorgi, 2012) because the open-ended research question suggested the need for an inductive approach (Palinkas, 2014). With this design, researchers elicit descriptions from several individuals who have had an experience and locate the common elements in the descriptions, thereby providing an understanding of the lived experiences of a phenomenon (Giorgi, 2012). There are three procedures necessary to locate the common elements: (a) phenomenological reduction, (b) free imaginative variation, and (c) identifying the invariant aspect(s), which is also referred to as distilling the essence (Giorgi, as cited in Patton, 2014).

The descriptive phenomenological approach allowed us to gain broader understanding of the experiences of participants while refraining from bias and researcher interpretation (Giorgi, Giorgi, \& Morley, 2017). Further, it allowed for the addition of a framework to structure the findings: ecological systems theory. Due to its use by counseling programs, counselor educators, and clinicians (Rogers, Gilbride, \& Dew, 2018), this framework had the potential to provide a practical context to disseminate the findings of this study (Reiners, 2012). Moreover, such contextualization is noted as a "core foundation of multicultural research" (Suarez-Balcazar, Balcazar, Garcia Ramirez, \& TaylorRitzler (2014, p. 535).

\section{Ecological Systems Theory}

Ecological systems theory enhances the understanding of the intersecting influences in complicated social experiences because, according to Bronfenbrenner (2000), all the contexts in which an individual exists are formative and require consideration. Ecological systems theory has been used as a framework in previous studies (e.g., Hooper, Wright, \& Burnham, 2012; Singer \& TummalaNarra, 2013) and, based on the complexities anticipated in counselor educators' experiences with emotionally charged exchanges while teaching multicultural counseling, we incorporated this theory to organize the data in this study. Bronfenbrenner introduced a model for ecological systems theory in the late 1970s, which was an elaboration on Lewin's theory of human behavior (Bronfenbrenner, 1977). Additionally, an adaptation of ecological systems theory has been applied to clinical treatment, referred to as the ecological systems perspective (Cook, Heppner, \& O'Brien, 2002). According to the ecological systems perspective, environmental and individual factors impact behaviors, behaviors result from reciprocal interactions between and among individuals and their environments, and meaning making influences behaviors (Cook, 2012). In his ecological systems model, Bronfenbrenner (2000) conceptualized contexts that are influential in a person's life as layers surrounding the individual. In an adaptation of ecological systems theory, Williams, McMahon, and Goodman (2015) have conceptualized the components in an ecological system as satellites revolving around an individual at the center.

In Bronfenbrenner's (1995) nested layers, the layer closest to an individual is known as the microsystem, which consists of the relationships and places in which a person directly participates (e.g., relationships with colleagues at work, family at home, or friends at a social spot). The next layer is the mesosystem, which consists of the different relationships in the microsystem that become 
interrelated (Hooper et al., 2012). For example, discord in a counselor educator's home might affect how that counselor educator interacts with students in the classroom, linking an educator's family and students. The next layer is the exosystem, which consists of entities that affect an individual without directly interacting with them (Bronfenbrenner, 1995). The American Counseling Association and Council for Accreditation of Counseling and Related Educational Programs (CACREP) are examples of entities in a counselor educator's exosystem because counselor educators follow their policies and guidelines. The macrosystem is the most distal layer, consisting of the patterns formed by social and institutional entities (Bronfenbrenner, 1995) and can impact people even without their input into the system (Hooper et al., 2012). An example the macrosystem's impact on counselor educators is that institutionalized biases can affect a classroom.

Ecological systems theory has evolved over time (Bronfenbrenner, 1986, 1995, 2000). After he first conceived his theory, Bronfenbrenner (1995) added a component referred to as the chronosystem, which encompasses transitions and cumulative effects. As explained later by Darling (2007), the person at the center also must be considered an entity of an ecological system. According to Giorgi (2012), human "consciousness is basically a medium between a person and the world" (p. 9), serving as a link between the individual layer and the remaining five layers in a person's ecological system. Thus, there are currently six components in an ecological system.

\section{Research Procedures}

\section{Role of the Researchers}

Researchers are the instruments in qualitative methods (Ponterotto, 2013). In phenomenological research, researchers must recognize preconceived notions about the phenomenon under investigation and engage in bracketing to suspend these thoughts and view data from an objective perspective (Englander, 2012; Giorgi et al., 2017). The primary investigator (PI) for this study was a female doctoral student in a counselor education and supervision program. The secondary investigator was a female counselor educator in a CACREP-accredited doctoral program. The PI completed the bracketing, interviews, and data analysis: Thus, the PI served in the role of an observer-participant. The secondary researcher provided feedback and triangulation of the data findings, acting in the role of cocreator in collaboration with the PI and participants.

\section{Data Collection}

The PI obtained institutional review board approval and used criterion and snowball sampling to locate a purposeful sample (Patton, 2014). The selection criteria included that the participants (a) had taught multicultural counseling at CACREP-accredited counselor education programs in the United States, (b) had taught multicultural counseling for a minimum of 1 year, (c) had taught multicultural counseling in the past year, and (d) had experienced emotionally charged exchanges while teaching multicultural counseling. Participants were located by calling counselor educators who had volunteered unsolicited assistance at professional conferences, screening them according to inclusion criteria, extending an invitation to participate to those who met the inclusion criteria, and obtaining referrals from participants.

Participants were recruited one at a time until saturation and redundancy were achieved (Patton, 2014) on the fourth interview. All the participants were women. One participant was Asian Indian, one was African American, and two were of Northern European descent. One participant was from the Northeast United States, and three were from the Midwest. The ages of the participants ranged between 31 and 60 . All the participants considered themselves typically able and had graduated from CACREP-accredited counselor education and supervision programs. Three had a Doctor of Philosophy degree, and one had a Doctor of Education degree. 
The participants' natural surroundings were the setting for each individual 90-min semistructured phone interview (Giorgi \& Giorgi, 2003) that elicited responses to nine open-ended questions (Englander, 2012) contained in an interview protocol, as well as several demographic questions (Rudestam \& Newton, 2015). The interview questions focused on the contexts of counselor educators' experiences with the phenomenon of interest and on what happened during those experiences (Ponterotto, 2013). The interview protocol was developed by reviewing interview questions used in previous studies of similar topics (Janesick, 2011). Prior to the interview, the participants provided informed consent to participate (American Counseling Association, 2014).

The participants expressed themselves freely during the interviews, no interviews ended prematurely, and no participants requested referral for postinterview support. The interviews were digitally recorded, and each recording was played to obtain a sense of the content (Giorgi \& Giorgi, 2003) before they were replayed and transcribed verbatim (Giorgi, 2012). All the data acquired from this study, except extraneous data, were described and reported accurately, and credit for the data belongs to the individuals who contributed to the study (Ponterotto, 2013).

\section{Data Analysis}

The PI conducted data analysis by hand, following the directions for descriptive phenomenology that were provided by Giorgi (2012). During phenomenological reduction, the PI set biases aside through bracketing, read the transcripts, identified meaning units, grouped similar meaning units together into parts, and assigned descriptive labels to the parts (Giorgi, 2012). Four hundred meaning units were derived from the four transcripts, and organization resulted in 68 parts. During free imaginative variation, the groups were aggregated more generally into 17 clusters and labeled (Giorgi, 2012). The clusters were further categorized by types (Miles, Huberman, \& Saldena, 2014), including the types of emotionally charged exchanges that the participants described, and the types of contexts in which the participants' had experiences. The ecological systems perspective (Cook, 2012) was used to delineate the types of contexts and organize emergent themes. Grouping the data by types resulted in seven themes, which reflected the invariant aspects of the participants' experiences, and descriptions of the participants' shared experiences were composed for each theme (Giorgi, 2012). The PI constructed the essence of the participants' experiences from these descriptions, including what the participants experienced (i.e., the textual description) and how they experienced it (i.e., the structural description; Ponterotto, 2013).

\section{Trustworthiness}

We employed several strategies to support the trustworthiness of this investigation. To ensure dependability, the PI maintained detailed records for the decisions made during data analysis. For confirmability, the PI prepared a detailed plan for the study, followed all the protocols established in the institutional review board application, and maintained fidelity to the descriptive phenomenological method. For credibility, the PI obtained rich, thick descriptions and adapted the interview protocol after each interview to gain more detail. Further, the scope of the clusters, themes, and essence was confined to the data the participants provided. For transferability, the PI and secondary investigator triangulated sources of the data (Guion, Diehl, \& McDonald, 2011), including from participant descriptions, researcher notes and intuition (Giorgi, 2012), and data from the literature that corroborated or conflicted with the findings (Patton, 2014). The PI implemented a system to find segments of text from the transcripts and analysis log to manage the data obtained from participant descriptions, and the invariant aspects (i.e., the essence) were derived from descriptions common to all participants.

\section{Results}

All of Bronfenbrenner's (2000) ecological layers were reflected in the seven themes that emerged from the data analysis: (a) participants' influences on the experiences (the individual at the center), 
(b) troubling emotions experienced (the microsystem), (c) pleasant emotions experienced (the microsystem), (d) mixed emotions experienced (the chronosystem), (e) influence of additional counselor educator roles on the experiences (the mesosystem), (f) influence of the course on the experiences (the exosystem), and (g) outcomes experienced (the macrosystem). Although the themes and layers of the participants' ecological system are listed as discrete entities, because the levels of an ecological system affect one another reciprocally and bidirectionally (Cook, 2012), additional ecological layers might also be relevant to the themes.

\section{Ecological Level: The Individual at the Center}

The first theme, participants' influences on the experiences, primarily reflected the individual(s) at the center of the ecological system.

\section{Theme 1: Participants' Influence on the Experiences}

The participants all considered themselves the initiators of emotionally charged exchanges (e.g., "I poke the bear") and described evoking their students' emotions during multicultural counseling courses (e.g., "I want them to feel, to experience this viscerally"). All the participants also recognized that their personal attributes contributed to their experiences of the exchanges: "My experiences shape how I perceive things."

All the participants' experiences were impacted by their commitment to teaching the course (e.g., "I literally cannot stop thinking the night before about the class"), as well as their expectancy about student development during the course (e.g., "[I explain that] it's important that you do ethical competent work with your clients"). The commitment and expectancy reflected a sense of purpose about teaching multicultural counseling (e.g., "I do believe that helping other people heal, for me, is an expression of spiritual wholeness").

\section{Ecological Level: The Microsystem}

Bronfenbrenner's (2000) microsystem was reflected in participants' experiences immediately before and after a peak moment of an emotionally charged exchange between and among students. The participants described experiencing both troubling and pleasant emotions at this level, which were the second (troubling emotions experienced) and third (pleasant emotions experienced) themes that emerged in the analysis of the data.

\section{Theme 2: Troubling Emotions Experienced}

All the participants described feeling scrutinized (e.g., "Everyone is looking at me and waiting for me to respond and see how I'm going to act"). All also described feeling inadequate (e.g., "I did not handle that well at all") at the time of an exchange. The intensity of the emotions during these experiences varied (from mild to strong), and the participants described openly expressing these emotions or keeping them private.

\section{Theme 3: Pleasant Emotions Experienced}

The participants did not directly associate pleasant emotions with emotionally charged exchanges, but described them indirectly. All the participants felt enjoyment (e.g., "I enjoy my work with the students") and compassion (e.g., "I need to strive to understand their narrative, their experiences"). They also all described experiencing an overarching sense of fulfillment: "I know that I'm doing what I'm supposed to do."

\section{Ecological Level: The Chronosystem}

The participants described experiencing residual emotions after the peak of an emotionally charged exchange, which represented the chronosystem (Bronfenbrenner, 2000). This resulted in 
experiencing a combination of residual and current emotions, or mixed emotions, which was the fourth theme.

\section{Theme 4: Mixed Emotions Experienced}

After having an emotionally charged exchange, all the participants described feeling tense during future multicultural counseling classes (e.g., "Anything I say incorrectly in their eyes, who knew the ramifications of that?"). Mixed emotions were prominent because once a participant had a troubling exchange, the memory of it lasted indefinitely while teaching the course in the future. As an example of mixed emotions, one participant stated, "It's also very exciting for me. . . So, along with the anxiety, there is excitement." All the participants also noted how earlier life experiences impacted their current experiences (e.g., "My own emotional reality early on was evident in my own emotional reaction to that exercise that brought tears to certain students, and my ignoring that and not attending to that was clearly connected to avoidance of highly emotional exchanges").

\section{Ecological Level: The Mesosystem}

Counselor educators' scholarly functions outside of teaching multicultural counseling are part of their mesosystem. The participants in this investigation shared that their roles in these functions, which comprises the fifth theme, interacted with their experiences of emotionally charged exchanges.

\section{Theme 5: Impact of Additional Roles on the Experiences}

The participants' experiences of emotionally charged exchanges related to teaching multicultural counseling occurred within the context of teaching other courses and carrying out a range of additional scholarly functions, as shown by a participant's remark: "It is a way to include all of my interests in practice, study, and scholarship, and then being able to convey my interest, and passion, and knowledge to preparing future practitioners." Although the participants had divergent reasons for becoming a counselor educator as well as for teaching multicultural counseling, they all had a sense of satisfaction with their counselor educator role, as reflected in a participant's statement: "I can't imagine a career that is more exciting, more meaningful." Reflective of the reciprocal interactions in ecological systems theory (Cook, 2012), the majority of the participants also described the impact of their multicultural educator role on relations with their colleagues (e.g., "There's a little bit of a tension with others because they know you're teaching that course") and on infusing multicultural counseling in other courses ("I'm very intentional, making sure it's infused in whatever I teach").

\section{Ecological Level: The Exosystem}

The sixth theme uncovered in data analysis, impact of the course on the participants' experiences, reflected exosystem influences because so many aspects of the course are determined without the participants' input. Institutional administrators who make decisions about student admissions and retention, tuition, and classroom environments are an example of entities in a counselor educator's exosystem.

\section{Theme 6: Impact of the Course on the Experiences}

The participants considered the course challenging to teach (e.g., "Teaching multicultural counseling is challenging, and it challenges me to the core every time"), with the course topics, processes, and classroom circumstances relevant to how the participants experienced emotionally charged exchanges (e.g., "I've been teaching it for so long, and every time it's different because ... in terms of who is in the room changes and shapes so much"). Concerning course processes, all the participants considered establishing trust necessary but difficult (e.g., "I have to work much harder to gain their trust"). The participants also considered openness with students essential and it was one of the ways that they developed trust. In particular, the participants were open about mistakes they had made, 
so students might feel less threatened if they made mistakes. For example, a participant shared, "I have to be very explicit about my own multicultural journey ... I talk about the mistakes I have made."

\section{Ecological Level: The Macrosystem}

The participants reflected the influence of the macrosystem (e.g., promoting social justice and advocacy) in their descriptions of the outcomes from emotionally charged exchanges, which comprised the seventh theme revealed during data analysis.

\section{Theme 7: Outcomes Experienced}

The participants expressed that teaching multicultural counseling was more than an academic endeavor to them (e.g., "With every class, I put my soul on the line"). Accordingly, they strived to transform emotionally charged exchanges into teachable moments: "The worst experience of the class became a really good one for them." The participants also developed themselves so that they were better equipped to respond in the future (e.g., "Teaching a multicultural counseling course and having difficult conversations is one of the main places where my growth happens").

\section{Essence}

The participants experienced troubling and pleasant emotions associated with emotionally charged exchanges. The emotions occurred immediately and residually, ranged from mild to strong in intensity, and were intertwined with the emotional undercurrents involved in teaching the course. The participants learned and were inspired to develop after experiencing emotionally charged exchanges, and they felt fulfilled overall by teaching multicultural counseling,

\section{Discussion}

The experiences of the counselor educators who participated in this study were complicated by multiple layers of emotionality that transcended time. The ecological systems lens captured the reciprocal influences of the undercurrents (e.g., expectancy and commitment), peak moments (e.g., scrutinized and inadequate), residual aftereffects (e.g., tension), and overarching emotions (e.g., fulfillment) on participants' experiences. Although the troubling aspects of the participants' experiences were of interest, mitigating influences were also evident, including enjoyment of positive interactions with students, reward from meeting ethical and teaching standards, esteem from actualizing a vital purpose, and the overarching sense of fulfillment from the growth that they achieved through teaching multicultural counseling, with that growth often spurred by the need to transform troubling exchanges into teachable moments. In sum, there was not a time during which participants were not experiencing the emotions associated with emotionally charged exchanges related to teaching multicultural counseling.

\section{Implications for Practice}

Previous findings indicated that counselor educators experienced discomfort while teaching multicultural counseling (Reynolds, 2011) and teaching multicultural counseling is more difficult than teaching other courses (Yoon et al., 2014). The results from this study confirm and extend these findings, which can inform the doctoral level curriculum in counselor education and supervision programs, as well as practicing counselor educators' pedagogy, to better enable students' multicultural counseling competence. This might lead to improved treatment for a diverse range of clients and reduce treatment disparities. The results also could initiate conversations among legal, credentialing, regulatory, professional, and teaching-learning institutions concerning relevant institutional values, cultures, policies, and structures. 


\section{Types and Scope of Discomfort}

The participants described the nature of the discomfort counselor educators might experience (e.g., feeling scrutinized, inadequate, and tense) as well as the scope of discomfort (e.g., immediately proximal to and residually after an exchange). Predicting that a problem might occur is a protective strategy (Toporek \& Worthington, 2014). The findings from this study enable counselor educators to predict the kind and duration of discomfort they might experience and, potentially, to protect themselves from effects of emotionally charged exchanges. Developing a plan to address known challenges is an effective coping strategy (Toporek \& Worthington, 2014). Counselor educators can evaluate themselves and plan for skills development (Burton \& Furr, 2014). For example, counselor educators can self-assess using the Multicultural Teaching Competencies Inventory (Prieto, 2012), and determine what training they need. This planning can contribute to multicultural counseling educators' success, as the participants' in this study noted that their experiences were shaped by how they responded to emotionally charged exchanges.

\section{Sources of Difficulty}

The participants in this study found that teaching multicultural counseling was burdensome, which confirmed previous studies suggesting that the content and processes involved in teaching multicultural counseling were a source of difficulty (Reynolds, 2011; Yoon et al., 2014). This study indicated how teaching multicultural counseling might be more difficult: The participants described engaging on a deep emotional level with their students through disclosure about their personal identity development, including the mistakes they had made. While modeling sensitive selfdisclosure can enhance multicultural counseling instruction (Nixon et al., 2010; Reynolds, 2011) and reduce student apprehension (Goodboy, Bolkan, Myers, \& Zhao, 2011), this study uncovered that the disclosure also impacts educators. Policies and strategies at the program and institutional levels can address the burden of multicultural counseling educators. For example, due to issues related to power and oppression that are relevant to the course (Goodrich \& Shin, 2013), the teaching role might need to be separated from the evaluator role in multicultural counseling education. Additionally, due to the influence of students' varying developmental levels (e.g., regarding their capacity for self-exploration, openness to be challenged, and desire to learn; Helms et al., 2003; Warner et al., 2013; Yoon et al., 2014), the position of the course in the curriculum might need consideration, such as offering it during the provisional student admission period when full admission is contingent on students' performance in the course. Without needed supports, counselor educators may avoid teaching multicultural counseling (Sue, Rivera, Capodilupo, Lin, \& Torino, 2010), "water down" (Yoon et al., 2014, p. 364) the challenging aspects of the course, avoid the discussions with the potential to lead to emotionally charged exchanges (Burton \& Furr, 2014), or ignore conflict if it occurs (Sue et al., 2010).

\section{Limitations}

The study relied on participants' subjective recollections, which might have differed from the actual events they recalled (Giorgi, 2012). The participants also might have intentionally altered details of the experiences that they shared such as withholding their actual views or slanting the information that they provided to appear in a more favorable light (Krumpal, 2013). Thus, there may be inaccuracies in the data collected. Additionally, we might have misunderstood participants' views and subjectively coded and categorized the data (Giorgi, 2012), which could have created inaccuracies in the data analysis.

\section{Recommendations for Further Study}

This topic warrants further investigation such as confirming the findings through a survey study with a greater number of participants. The current findings also might be extended by further study of the various emotional experiences that the participants described. For example, a study on the 
ongoing tension the participants described might investigate whether multicultural counseling educators' uncertainty about institutional supports correlates with the tension they feel.

\section{Conclusion}

Although the literature had established that teaching multicultural counseling might evoke strong student emotions, this study revealed that it also might evoke strong counselor educator emotions: The ecological systems perspective revealed a complex array of counselor educator emotions across social contexts. In summary, the participants experienced preparing future counselors to be multiculturally competent as more difficult than teaching other courses, yet more rewarding. Uncovering this lived experience has established a basis for further conversation and study.

\section{References}

American Counseling Association. (2014). 2014 code of ethics. Alexandria, VA: Author.

Ametrano, I. M. (2014). Teaching ethical decision making: Helping students reconcile personal and professional values. Journal of Counseling \& Development, 92, 154-161. doi:10.1002/j.15566676.2014.00143.x

Arredondo, P., \& Tovar-Blank, Z. G. (2014). Multicultural competencies: A dynamic paradigm for the 21st century. In F. T. Leong, L. Comas-Díaz, G. C. Nagayama Hall, V. C. McLoyd, \& J. E. Trimble (Eds.), APA handbook of multicultural psychology, 2: Applications and training (pp. 19-34). Washington, DC: American Psychological Association. doi:10.1037/14187-002

Bronfenbrenner, U. (1977). Towards an experimental ecology of human development. American Psychologist, 32, 513-531. doi:10.1037/0003-066X.32.7.513

Bronfenbrenner, U. (1986). Ecology of the family as a context for human development: Research perspectives. Developmental Psychology, 22, 723-742. doi:10.1037/0012-1649.22.6.723

Bronfenbrenner, U. (1995). Developmental ecology through space and time: A future perspective. In Moen, P., Elder, G. H., Jr., \& Luscher, K. (Eds.), Examining lives in context: Perspectives on the ecology of human development (pp. 619-647). Washington, DC: American Psychological Association.

Bronfenbrenner, U. (2000). Ecological systems theory. In A. E. Kazdin (Ed.), Encyclopedia of psychology (Vol. 3, pp. 129-133). Washington, DC: American Psychological Association.

Burton, S., \& Furr, S. (2014). Conflict in multicultural classes: Approaches to resolving difficult dialogues. Counselor Education and Supervision, 53, 97-110. doi:10.1002/j.15566978.2014.00051.x

Cook, E. P. (2012). Understanding people in context: The ecological perspective in counseling. Alexandria, VA: American Counseling Association.

Cook, E. P., Heppner, M. J., \& O’Brien, K. M. (2002). Career development of women of color and White women: Assumptions, conceptualization, and interventions from an ecological perspective. The Career Development Quarterly, 50, 291-305. doi:10.1002/j.21610045.2002.tb00574.x

Darling, N. (2007). Ecological systems theory: The person in the center of the circles. Research in Human Development, 4, 203-217. doi:10.1080/15427600701663023

Dickson, G. L., Argus-Calvo, B., \& Tafoya, N. (2010). Multicultural counselor training experiences: Training effects and perceptions of training among a sample of predominately Hispanic students. Counselor Education and Supervision, 49, 247-265. doi:10.1002/j.1556-

6978.2010.tb00101.x 
Englander, M. (2012). The interview: Data collection in descriptive phenomenological human scientific research. Journal of Phenomenological Psychology, 43, 13-35. doi:10.1163/156916212X632943

Francis, P. C., \& Dugger, S. M. (2014). Professionalism, ethics, and value-based conflicts in counseling: An introduction to the special section. Journal of Counseling \& Development, 92, 131-134. doi:10.1002/j.1556-6676.2014.00138.w

Frisby, B. N., \& Martin, M. M. (2010). Instructor-student and student-student rapport in the classroom. Communication Education, 59, 146-164. doi:10.1080/03634520903564362

Giorgi, A. (2012). The descriptive phenomenological psychological method. Journal of Phenomenological Psychology, 43, 3-12. doi:10.1163/156916212X632934

Giorgi, A., \& Giorgi, B. (2003). The descriptive phenomenological psychological method. In P. M. Camic, J. E. Rhodes, \& L. Yardley (Eds.), Qualitative research in psychology: Expanding perspectives in methodology and design (pp. 243-273). Washington, DC: American Psychological Association.

Giorgi, A., Giorgi, B., \& Morley, J. (2017). The descriptive phenomenological psychological method. In C. Willig \& W. Stainton-Rogers (Eds.), The Sage handbook of qualitative research in psychology (pp. 176-192). Thousand Oaks, CA: Sage.

Goodboy, A. K., Bolkan, S., Myers, S. A., \& Zhao, X. (2011). Student use of relational and influence messages in response to perceived instructor power use in American and Chinese college classrooms. Communication Education, 60, 191-209. doi:10.1080/03634523.2010.502970

Goodrich, K. M., \& Shin, R. Q. (2013). A culturally responsive intervention for addressing problematic behaviors in counseling students. Counselor Education and Supervision 52, 4355. doi:10.1002/j.1556-6978.2013.00027.x

Guion, L. A., Diehl, D. C., \& McDonald, D. (2011). Triangulation: Establishing the validity of qualitative studies. Gifted Child Today, 35, 72-73. doi:10.1177/1076217511428309

Helms, J. E., Shakes Malone, L., Henze, K., Satiani, A., Perry, J., \& Warren, A. (2003). First annual diversity challenge: "How to survive teaching courses on race and culture." Journal of Multicultural Counseling and Development, 31, 3-11. doi:10.1002/j.2161-1912.2003.tb00525.x

Hill, N. R., Vereen, L. G., McNeal, D., \& Stotesbury, R. (2013). Multicultural awareness, knowledge, and skills among American counselor trainees: Group differences in self-perceived competence based on dispositional and programmatic variables. International Journal of Advocacy in Counselling, 35, 261-272. doi:10.1007/s10447-012-9181-5

Hooper, L. M., Wright, V. H., \& Burnham, J. J. (2012). Acculturating to the role of tenure-track assistant professor: A family systems approach to joining the academy. Contemporary Family Therapy, 34, 29-43. doi:10.1007/s10591-011-9171-5

Howell, J. L., Gaither, S. E., \& Ratliff, K. A. (2015). Caught in the middle: Defensive responses to IAT feedback among Whites, Blacks, and biracial Black/Whites. Social Psychological and Personality Science, 6, 373-381. doi:10.1177/1948550614561127

Janesick, V. J. (2011). “Stretching” exercises for qualitative researchers (3rd ed.). Thousand Oaks, CA: Sage.

Krumpal, I. (2013). Determinants of social desirability bias in sensitive surveys: A literature review. Quality \& Quantity, 47, 2025-2047. doi:10.1007/s11135-011-9640-9

Miles, M. B., Huberman, A. M., \& Saldana, J.(2014). Qualitative data analysis: A methods sourcebook (3rd ed.). Thousand Oaks, CA: Sage. 
Mindrup, R. M., Spray, B. J., \& Lamberghini-West, A. (2011). White privilege and multicultural counseling competence: The influence of field of study, sex, and racial/ethnic exposure. Journal of Ethnic \& Cultural Diversity in Social Work, 20, 20-38. doi:10.1080/15313204.2011.545942

Nixon, D., Marcelle-Coney, D., Torres-Greggory, M., Huntley, E., Jacques, C., Pasquet, M., \& Ravachi, R. (2010). Creating community: Offering a liberation pedagogical model to facilitate diversity conversations in MFT graduate classrooms. Journal of Marital and Family Therapy, 36, 197-211. doi:10.1111/j.1752-0606.2009.00180.x

Palinkas, L. A. (2014). Qualitative and mixed methods in mental health services and implementation. Journal of Clinical Child \& Adolescent Psychology, 43, 851-861. doi:10.1080/15374416.2014.910791

Patton, M. Q. (2014). Qualitative research \& evaluation methods (3rd ed.). Thousand Oaks, CA: Sage.

Pernell-Arnold, A., Finley, L., Sands, R. G., Bourjolly, J., \& Stanhope, V. (2012). Training mental health providers in cultural competence: A transformative learning process. American Journal of Psychiatric Rehabilitation, 15, 334-356. doi:10.1080/15487768.2012.733287

Ponterotto, J. G. (2013). Qualitative research in multicultural psychology: Philosophical underpinnings, popular approaches, and ethical considerations. Qualitative Psychology, 1, 19-32. doi:10.1037/2326-3598.1.S.19

Prieto, L. R. (2012). Initial factor analysis and cross-validation of the multicultural teaching competencies inventory. Journal of Diversity in Higher Education, 5, 50-62. doi:10.1037/a0026199

Reiners, G. (2012). Understanding the differences between Husserl's (descriptive) and Heidegger's (interpretive) phenomenological research. Journal of Nursing Care, 1, 1-5. doi:10.4172/21671168.1000119

Reynolds, A. L. (2011). Understanding the perceptions and experiences of faculty who teach multicultural counseling courses: An exploratory study. Training and Education in Professional Psychology, 5, 167-174. doi:10.1037/a0024613

Rogers, J. L., Gilbride, D. D., Dew, B. J. (2018). Utilizing an ecological framework to enhance counselors' understanding of the U.S. opioid epidemic. The Professional Counselor, 8, 226239. doi:10.15241/jlr.8.3.226

Rudestam, K. E., \& Newton, R. R. (2015). Surviving your dissertation. Los Angeles, CA: Sage.

Singer, R. R., \& Tummala-Narra, P. (2013). White clinicians' perspectives on working with racial minority immigrant clients. Professional Psychology: Research and Practice, 44, 290-298. doi:10.1037/a0034299

Smith, T. B., \& Trimble, J. E. (2016). Foundations of multicultural psychology: Research to inform effective practice. Washington, DC: American Psychological Association. doi:10.1037/14733000

Suarez-Balcazar, Y., Balcazar, F., Garcia-Ramirez, M., \& Taylor-Ritzler, T. (2014). Ecological theory and research in multicultural psychology: A community psychology perspective. In F. T. Leong, L. Comas-Díaz, G. C. Nagayama Hall, V. C. McLoyd, \& J. E. Trimble (Eds.), APA handbook of multicultural psychology, 1: Theory and research (pp. 535-552). Washington, DC: American Psychological Association.

Sue, D. W., Rivera, D. P., Capodilupo, C. M., Lin, A. I., \& Torino, G. C. (2010). Racial dialogues and White trainee fears: Implications for education and training. Cultural Diversity and Ethnic Minority Psychology, 16, 206-214. doi:10.1037/a0016112 
Swank, J. M., \& Adcock, S. (2014). Gatekeeping during admissions: A survey of counselor education programs. Counselor Education and Supervision, 53, 47-61. doi:10.1002/j.15566978.2014.00048.x

Toporek, R. L., \& Worthington, R. L. (2014). Integrating service learning and difficult dialogues pedagogy to advance social justice training. The Counseling Psychologist, 42, 919-945. doi:10.1177/0011000014545090

Warner, C. B., Phelps, R. E., Pittman, D. M., \& Moore, C. S. (2013). Anticipating and working with controversy in diversity and social justice topics. In D. S. Dunn, R. A. Gurung, K. Z. Naufel, \& J. H. Wilson (Eds.), Controversy in the psychology classroom: Using hot topics to foster critical thinking (pp. 143-156). Washington, DC: American Psychological Association. doi:10.1037/14038-009

Williams, J. M., McMahon, H. G., \& Goodman, R. D. (2015). Eco-webbing: A teaching strategy to facilitate critical consciousness and agency. Counselor Education and Supervision, 54, 82-97. doi:10.1002/ceas. 12006

Yoon, E., \& Jérémie-Brink, G., \& Kordesh, K. (2014). Critical issues in teaching a multicultural counseling course. International Journal for Advocacy in Counselling, 36, 359-371.

The Journal of Educational Research and Practice provides a forum for studies and dialogue that allows readers to better develop social change in the field of education and learning. Journal content may focus on educational issues of all ages and in all settings. It also presents peer-reviewed commentaries, book reviews, interviews of prominent individuals, and additional content. The objectives: We publish research and related content that examines current relevant educational issues and processes aimed at presenting readers with knowledge and showing how that knowledge can be used to impact social change in educational or learning environments. Additional content provides an opportunity for scholarly and professional dialogue regarding that content's usefulness in expanding the body of scholarly knowledge and increasing readers' effectiveness as educators. The journal also focuses on facilitating the activities of both researcher-practitioners and practitioner-researchers, providing optimal opportunities for interdisciplinary and collaborative thought through blogging and other communications. Walden University Publishing: http://www.publishing.waldenu.edu 